\title{
Cohabitation and Marriage Intensity
}

\section{Consolidation, Intimacy, and Commitment}

Michael Pollard and Kathleen Mullan Harris

RAND Labor \& Population

WR-1001

June 2013

This paper series made possible by the NIA funded RAND Center for the Study of Aging (P3OAG012815) and the NICHD funded RAND Population Research Center (R24HD050906).

RAND working papers are intended to share researchers' latest findings and to solicit informal peer review. They have been approved for circulation by RAND Labor and Population but have not been formally edited or peer reviewed. Unless otherwise indicated, working papers can be quoted and cited without permission of the author, provided the source is clearly referred to as a working paper. RAND's publications do not necessarily reflect the opinions of its research clients and sponsors. RANDß is a registered trademark. 


\title{
Cohabitation and Marriage Intensity: Consolidation, Intimacy, and Commitment
}

\author{
Michael S. Pollard* and Kathleen Mullan Harris** \\ * RAND, Santa Monica, CA \\ ** University of North Carolina - Chapel Hill
}

Corresponding Author: Michael S. Pollard, RAND Corporation, 1776 Main Street, Santa Monica, CA 90407-2138. Phone 310-393-0411 x7627; Fax 310-260-8160;

E-mail: mpollard@,rand.org

Work on this project was supported by grant R03 HD060731 from the National Institute on Child Health and Human Development (PI: Michael Pollard).

This research uses data from Add Health, a program project designed by J. Richard Udry, Peter S. Bearman, and Kathleen Mullan Harris, and funded by a grant P01-HD31921 from the National Institute of Child Health and Human Development, with Cooperative funding from 17 other agencies. Special acknowledgment is due Ronald R. Rindfuss and Barbara Entwisle for assistance in the original design. Persons interested in obtaining data files from Add Health should contact Add Health, Carolina Population Center, 123 W. Franklin Street, Chapel Hill, NC 27516-2524 (addhealth@unc.edu) 


\section{Describing Cohabitation and Marriage in Add Health}

Changes in union formation in the United States over the last four decades are well documented but poorly understood. The Census Bureau and various national surveys have tracked rising and now stable but high divorce rates, the postponement of marriage and recent declines in marriage rates, and the relatively recent rise in cohabitation (Bumpass 1990; Cherlin 1992; Fitch and Ruggles 2000; Raley 2000; U.S. Bureau of the Census 1998). The trends suggest that young people are not turning away from coupling or establishing intimate relations with a romantic partner as rates of "union formation," including both marital and cohabiting unions, have remained fairly stable over time (Raley 2000; Bumpass, Sweet, and Cherlin 1991). Concern exists, however, on the apparent substitution by more casual often short-term unions for the more traditional unions that provide greater economic security and emotional stability for family formation. In contemporary U.S. society, intimate relationships that progress towards coresidential conjugal unions no longer imply marriage, and knowledge about the meaning and contexts of cohabiting unions is hard to find.

Because the rise in cohabitation has been relatively recent, it has taken some time for our federal statistics to officially measure and track such unions (see Casper and Cohen 2000). Understanding and documenting trends in cohabitation therefore has fallen primarily on surveys as the major source of data. Although measurement of cohabitation is discussed (as a limitation) in use of census data (Casper and Cohen 2000), measurement issues rarely come in reviews of research on cohabitation using survey data (e.g., Smock 2000). Yet relationship and individual characteristics of cohabiting couples are routinely contrasted with married couples in an effort to understand differences and similarities in these two union types (e.g., Brines and Joyner 1999; Brown and Booth 1996; Nock 1995; Rindfuss and VandenHeuvel 1990). Before we can make 
progress in better understanding the meaning of cohabitation for young couples today and the relationship between cohabitation and marriage, we need to assess the measurement and quality of data on cohabitation.

In this paper we report on cohabitation and marriage data coming from the third wave of the National Longitudinal Study of Adolescent Health, or Add Health, a national longitudinal study of adolescents and young adults beginning in 1995 that has been funded by NICHD and 17 other federal agencies. Add Health respondents were aged 18-26 in Wave III (2001-02) when romantic relationships are particularly salient in young people's lives and tend to become more serious and intimate as they take on adult roles and responsibilities. Add Health employed several innovative methods to measure cohabitation and to better understand the relationship dynamics of cohabiting unions in ways that are similar to marital unions. We present two different ways to measure cohabiting unions according to the length of time a couple has "lived together" and the implications of different definitions for the levels of cohabitation in the Add Health sample. We also develop measures that capture domains of relationship functioning, quality, and intimacy and contrast these aspects of relationships by cohabitation and marital status and by the duration of the relationship. Finally, we are able to contrast cohabiting relationships with married relationships according to whether cohabitation preceded marriage to obtain further insights into the different contexts of these relationships and the extent to which we can observe a continuum of relationship intensity in our various measures across the different types of relationships.

\section{The National Longitudinal Study of Adolescent Health}

The National Longitudinal Study of Adolescent Health, or Add Health is a nationally 
representative study of adolescents in grades 7 through 12 in the United States in 1995 who have been followed with multiple interview waves into young adulthood. A sample of 80 high schools and 52 middle schools from the US was selected with unequal probability of selection. Incorporating systematic sampling methods and implicit stratification into the Add Health study design ensured this sample is representative of US schools with respect to region of country, urbanicity, school size, school type, and ethnicity. A sample of adolescents and one of their parents was selected from school rosters for in-home interviews which were conducted between April and December 1995, yielding Wave I data with a total sample size of 20,745 adolescents aged 12-19. All adolescents in grades 7 through 11 in Wave I were followed up one year later for the Wave II in-home interview in 1996.

In 2001-02 a third in-home interview was conducted with the original respondents from Wave I as they were now aged 18-26 and entering the transition to adulthood. The Wave III interview was designed to collect data on attitudes, behaviors and outcomes in the domains of late adolescence and young adult life, with particularly rich and detailed data on romantic relationships, and union and family formation behaviors. Over 15,000 Add Health respondents were re-interviewed at Wave III with longitudinal data over the various waves of interviews. See Harris et al. (2003) for more details on the Add Health design and longitudinal data.

For the present analysis of cohabitation and marriage data in Add Health, we do not impose any sample restrictions and use data from respondents with Wave I and Wave III data yielding a sample size of 15,197 men and women. Our analyses, however, are based on varying samples of relationships because individuals can have multiple relationships and therefore contribute multiple observations to a sample of relationships. In addition, Add Health screened for certain types of relationships to meet the needs of different research questions, and samples 
therefore vary according to the questions asked of different types of relationships (described below). In all analyses, we use the Wave III sampling weights that adjust for the complex sampling design and attrition to Wave III.

\section{Data on Cohabitation and Marriage}

Data on cohabitation and marriage come from two different sections of the Wave III interview in Add Health. One section uses the traditional approach of asking respondents for a history of all marriage and "marriage-like" relationships, which involves reporting dates of relationship beginning and ending for each type of relationship, and if the relationship ended, how it ended. With the beginning and ending dates, event history data can be assembled and survival analysis of entry into cohabitation or marriage and durations of cohabitation and marriage can be conducted. It is important to note that cohabitations ("marriage-like" relationships) were asked to be reported if they lasted for one month or more.

A second set of data on cohabitation and marriage comes from the relationship section of the questionnaire. Add Health collected a relationship history at Wave III by asking respondents to list all romantic and sexual relationships in which the respondent was involved for 3 months or longer in the last 6 years (to cover the time period dating back to the Wave I interview when data on romantic and sexual relationships were previously collected). Then, for each partner in a relationship, a series of questions were asked, including dates and length of relationship, the sex, age, race, and Hispanic origin of partner, whether the relationship was a sexual relationship, type of relationship (cohabitation, marriage, dating), and a detailed pregnancy/fertility history within the relationship. 


\section{Types of Relationships}

To accommodate various funded research projects on relationships, Add Health developed a strategy in Wave III to identify three distinct but not mutually exclusive groups of relationships based on the relationship history that respondents provided: all sexual relationships, the two "most important" relationships, and a third set of relationships was identified to include a sample of 1,500 "couples" in which the Add Health respondent agreed to recruit their partner to participate in the survey and complete an identical Wave III questionnaire. Eligibility criteria for the "couples sample" required that partners had to be opposite sex, 18 years old or older, and in a relationship with the main respondent lasting three months or longer. In the field work on Wave III, Add Health filled quotas of 500 dating, 500 cohabiting, and 500 married couples for the "couples sample," although eligibility for the couples sample was assessed during the interview.

The complex sample arrangements for relationships in Add Health Wave III have implications for the analysis options that are available. Specifically, the particular samples available for particular questions may be different, depending on how relationships samples overlap. The "sexual relationships" sample contains information on 34,167 relationships; the "important relationships" sample contains information on 19,727 relationships; and the "couples sample" contains information on 4,010 relationships. Recall that these samples are not mutually exclusive; 3,700 relationships were members of all three samples, while 14,914 more relationships qualified for two of the samples. Each sample received specialized questionnaire content, in addition to the base relationships information, and thus sample sizes for some questions are substantially different than others. For example, questions intended for the "couples sample" (such as maintenance of another residence or commitment to partner) refer 
only to current relationships and thus have smaller sample sizes available than other questions, such as whether partners have a joint bank account (asked of both the "couples" and "important relationships" samples), or relationship exclusivity, which was asked for all relationships.

\section{Plan for Descriptive Analysis}

First we construct life table estimates of the entry into nonmarital cohabitation from the complete marriage and cohabitation history data available in two different sections of the Wave III questionnaire (i.e., marriage and cohabitation history section and relationship history section). As we show, the estimates of cohabitation experience are sensitive to the way cohabitation is defined (in terms of minimum coresidence duration). Next, we delve into the detailed relationship data to examine several different dimensions of relationships that can be addressed by Add Health: consolidation, intimacy, and commitment. These dimensions are discussed in more detail below, and may be compared for relationships of different durations and contrasted with marital relationships along the same dimensions. While nonmarital cohabitation may serve as an alternative living arrangement to marriage for some individuals, it is most often considered to be a transitional arrangement between singlehood and formalized marriage. Within cohabitation, however, we can anticipate a range of relationships that each fall along a spectrum of relationship intensity, from unions where partners are more like singles at the lower-intensity end, to unions where partners are more like married couples at the more intense end.

\section{Entry into Cohabitation}


Using weighted data from the complete cohabitation histories we are able to construct life table estimates of the entry into first cohabitation for males and females by a variety of background characteristics. Here we show race/ethnic differences, as well as by father's education measured in adolescence (Wave I) as a proxy for socioeconomic background. Figure 1 plots the life table cumulative probability curves for females by age $(\mathrm{N}=8,123)$, or the proportion of females who have ever cohabited beginning at age 12, by race/ethnicity. From the Figure we see considerable diversity in cohabitation experience. Half of the white females have entered a cohabitation by age 23, while for black and Hispanic women the comparable age is 25 . By age 25 , only $40 \%$ of 'other' women (primarily Asian) have cohabited.

[Figure 1 About Here]

Figure 2 presents probability curves for males $(\mathrm{N}=7,161)$. Males enter cohabiting unions at a slower pace then females. Black males experience cohabitation more rapidly than other race/ethnicity groups, with half having entered a cohabitation by age 24 . Half of white males have entered a cohabitation by age 25 , while only $40 \%$ of Hispanic and 'other' males have cohabited by age 24 .

\section{[Figure 2 About Here]}

It is important to note what minimum relationship duration is used when defining a cohabiting union. The probability curves calculated above were based on the respondents' reports of living 'in a marriage-like relationship' with someone for a month or longer. For instance, if the minimum necessary amount of time spent together is increased modestly (by the survey instrument, for example), to "three or more months", there is a substantial impact on the identification of cohabitation. Figure 3 presents probability curves for males and females using both "one or more" and "three or more" month restrictions. From the curves we can see that 
increasing the minimum length of cohabiting from one month to three months substantially reduces estimates of cohabitation experience. The median age at entry to cohabitation for females overall shifts up one year, from 24 to 25 , with the $3+$ month definition. Furthermore, under this definition, slightly less than half (49\%) of the males enter cohabitation by age 28 , compared to a median age of entry to cohabitation of 25 when considering cohabitations of one or more months duration.

[Figure 3 About Here]

From Figure 3 we can see that there are many short term cohabitation experiences. That is, the differences in the probability curves based on one-month minimum durations versus threemonth minimum durations are quite large, with one- to two-month cohabitations comprising $15 \%$ of all reported cohabitation experiences. Further, these extremely short duration cohabitations are not simply recently entered current cohabitations censored by the survey (i.e., cohabitations begun within three months of the interview date), or brief periods of cohabitation immediately prior to marriage $-10 \%$ of all cohabitations reported (weighted) by Add Health respondents lasted less than three months from start to finish. Cohabitation is often described as a brief or unstable union form because most cohabitations have dissolved or converted into legal marriage within five years (e.g., Booth and Crouter 2002) - however clearly the ephemeral nature of many of these cohabitations is still underestimated.

Finally, the probability curves in Figure 3 also demonstrate that these very short term cohabitation experiences occur over all the ages considered, rather than being characteristic of only young people. For both males and females, the divergence between all cohabitations and only $3+$ month cohabitations grows across age, indicating that these short-term cohabitations continue to be experienced at each age. If these short term cohabitations were associated solely 
with teenagers, for example, the probability curves would stop diverging and continue parallel beyond the teen years.

Figures $4 \mathrm{~A}$ and $4 \mathrm{~B}$ present entry into cohabitation by father's (resident and nonresident, respectively) educational attainment for females. Resident (both biological and non-biological) father's education (see Figure 4A) is clearly associated with the propensity and timing of a daughter's cohabitation; higher levels of paternal educational attainment are associated with slower and lower entry into nonmarital cohabitation, ranging from $65 \%$ to roughly $45 \%$ of daughters having cohabited by age 27 (for fathers with a high school degree or less, and a college degree or higher, respectively). The association between nonresident (biological only) father's education and daughter's entry into cohabitation (see Figure 4B) is substantially weaker, and by age 26 roughly $70 \%$ of all daughters have cohabited regardless of nonresident father's education. Analogous results are presented for males in Figures 5A and 5B. Similar associations are observed, although the results are less distinct for males with resident fathers, and nonresident father's education has no consistent effect on transition to cohabitation.

[Figures 4A, 4B, 5A and 5B About Here]

\section{Relationship Intensity: Contrasting Cohabitation with Marriage}

As mentioned above, Add Health provides information on various dimensions of many of the relationships captured in the cohabitation and marriage histories. Specifically, we can examine relationship dynamics involving the concepts of consolidation, intimacy, and commitment within specific relationships. Together, these three dimensions speak to the overall 'intensity' of the relationship, which may be a useful analytical concept in conjunction with, or in place of, relationship status (i.e., cohabiting, legally married). 
Consolidation within a relationship refers to the degree to which individuals in a couple merge their (financial, physical, etc.) resources together, rather than maintaining them separately. In Add Health, consolidation can be operationalized as whether the couple maintained a joint bank account, whether the couple purchased anything together that cost more than $\$ 500$, and whether either partner maintained a separate residence where they kept clothing or toiletries and sometimes spent the night.

Intimacy can be assessed in Add Health by reports of how much the respondent loved his or her partner, how much the respondent thought his or her partner loved them, satisfaction with the relationship, and the number of meals eaten together per week (demonstrating shared time). Additionally, respondents were asked to indicate how close they felt to their (current) partner by selecting an image from a series of seven pairs of overlapping circles representing "self" and "other". The images ranged from no overlap to nearly complete overlap. Here we focus on the respondents identifying the image indicating maximum closeness.

Finally, level of commitment within (current) relationship can be assessed using the direct question "how committed are you to your relationship with [partner]?" with responses ranging from 1 ("completely committed") to 5 ("not at all committed"). Further, respondents were asked how likely their relationships with their partners were permanent, ranging from 1 ("almost certain") to 5 ("almost no chance"). For cohabiting relationships, commitment can also be estimated by whether the couple was engaged, and the level of self-reported exclusivity in the relationship (e.g., the respondent exclusively dated their partner, dated others concurrently, etc.).

These dimensions can be contrasted across relationship types (cohabitation, marriages that were preceded by cohabitation, and marriage without prior cohabitation), as well as across relationship duration, in order to get a sense of how the intensity of cohabitating relationships 
compares with marriages, and how the intensity of relationships changes with relationship duration. Following the assumption that cohabitation is largely a transitional union form, we might expect that cohabiting relationships report lower levels of intensity on all these dimensions than marriages, but that greater intensity is associated with longer relationship durations.

Turning first to consolidation, Panel A in Table 1 summarizes the (weighted) female responses to the consolidation questions by union type (cohabitation, marriage preceded by cohabitation, and marriage without cohabitation). Consolidation by union duration is also displayed for cohabitation and for marriage (both types combined). Results in the table indicate that both measures of economic consolidation are significantly lower for cohabitors than for married relationships. Only $16.1 \%$ of women in cohabitations report joint bank accounts with their partners, compared with $68.5 \%$ of women in marriages that were preceded by cohabitation, and $72.1 \%$ of women in marriages without prior cohabitation. Similarly, $40.1 \%$ of cohabiting women report having purchased something over $\$ 500$ with their partners, compared with more than $80 \%$ of women in both types of marriage. Additionally, slightly more cohabiting women report maintaining a separate residence than they believe their partners do (17.8\% versus $13.0 \%)$.

\section{[Table 1 About Here]}

Directing attention to consolidation at different union durations (less than 6 months, 6 months to a year, and over a year), there are significant increases in consolidation associated with longer durations for both cohabitations and marriages, but we can see that cohabitations of more than a year still do not obtain the same levels of consolidation as marriages of less than 6 months. For instance, $18 \%$ women in cohabitations of less than 6 months report purchasing something more than $\$ 500$ with their partners, while after a year, the number rises to $55 \%$. 
However, more than two-thirds (67\%) of women in marriages of less than 6 months report similar purchases.

Panel B in Table 1 presents measures of intimacy in the same fashion as consolidation. Overall, cohabitors generally report significantly lower levels of intimacy than women in marriages not preceded by cohabitation, who in turn report (nonsignificantly) lower levels of intimacy than women who married after cohabiting with their partner. However, contrasting relationship types reveals no significant differences in reports of perceived partner's love for respondent or meals together. Significantly higher intimacy levels are generally associated with longer relationship durations for both cohabitation and marriage, and here cohabitations of more than a year begin to approximate the same intimacy levels as marriages of less than 6 months.

Finally, in Panel C of Table 1 we see significantly lower levels of reported commitment and relationship longevity for cohabitations relative to marriages. We further note that $83 \%$ of cohabitors are dating their partner exclusively, and that $31 \%$ of them are engaged. Commitment in cohabitations generally increases with relationship duration, but the percentage of cohabitors reporting "completely committed" does not. Levels of commitment do not change significantly across marital relationship duration, but are significantly higher at each duration than those reported for cohabitations of more than a year.

Similar information for males is presented in Table 2, and the substantive results are virtually identical as for females. Cohabitors report significantly lower levels of consolidation, intimacy, and commitment than married males, and levels of consolidation, intimacy, and commitment increase with relationship duration. Once again, however, cohabitations of more than a year generally do not reach the intensity levels of marriages of less than 6 months.

Contrasting the responses of males and females within cohabitation reveals that 
cohabiting males report significantly lower levels of consolidation (fewer joint bank accounts and more other residences, $p<.1$ and $p<.01$, respectively), a significantly lower percent report "loves partner a lot" $(p<.001)$, and significantly less commitment on all four measures $(p<$ .001) than cohabiting females (results not shown). Differences between males and females in marriages and marriages preceded by cohabitation are not significant.

[Table 2 About Here]

\section{Discussion}

The results in Tables 1 and 2 present a consistent picture of cohabiting unions: the intensity of cohabiting relationships (conceptualized along three dimensions: consolidation, intimacy, and commitment) falls below that reported for married relationships. In terms of consolidation, cohabiting couples report substantially less joint economic circumstance than married relationships. Also as we might expect, cohabiting individuals are increasingly less likely to maintain a separate residence as the cohabiting union continues, suggesting that there is a gradual "move into" or consolidation of a single residence. However, comparing the male and female responses suggests that males are more likely to maintain separate residences deeper into the cohabiting relationship than females $(13 \%$ of females vs. $19 \%$ of males reported separate residences in cohabitations of more than a year in duration).

Cohabiting relationships are also associated with lower levels of reported closeness, love, and satisfaction in the intimacy dimension. Cohabitations of longer durations are associated with higher levels of love and closeness, although we can not discern from the tables whether these increase with the duration of relationships, or whether relationships with higher intimacy are less likely to be dissolved. It is also interesting to note that partners in marriages preceded by 
cohabitation generally report slightly higher levels of intimacy than partners in marriages that were not preceded by cohabitation.

Finally, as we would anticipate, cohabitors are also substantially less certain about the permanence of their relationships than respondents in married relationships, and they report substantially lower levels of "complete" commitment to their partner, especially for males. The prevalence of very short (less than 3 month) duration cohabitations indicated in Figure 3 also reflects these reports. Not surprisingly, levels of commitment in cohabiting unions are higher at longer durations. Additionally, male cohabitors broadly report lower levels of relationship intensity than female cohabitors.

Taken together, the results indicate a distinct difference in relationship intensity between cohabiting and married couples, with little overlap; married relationships of any duration consistently ranked higher on all of the intensity measures than cohabitations at even the longer durations. The findings support the notion that there are a range of relationships within the category of cohabitation, and that there may be some threshold intensity level within cohabitations at which point cohabitors choose to formalize the union and marry. 


\section{References}

Booth, A. and A. C. Crouter (eds.). 2002. Just Living Together: Implications of Cohabitation on Families, Children, and Social Policy. Mahwah, NJ: Lawrence Earlbaum.

Brines, J. and K. Joyner. 1999. "The Ties that Bind: Commitment an Stability in the Modern Union." American Sociological Review 64: 333-356.

Brown, S.L. and A. Booth. 1996. "Cohabitation Versus Marriage: A Comparison Of Relationship Quality." Journal of Marriage and the Family 58: 668678.

Bumpass, L.L. 1990. "What's Happening to the Family? Interactions Between Demographic and Institutional Change." Demography 27:483-98.

Bumpass, L.L., J.A. Sweet, and A. Cherlin. 1991. "The Role of Cohabitation in Declining Rates of Marriage." Journal of Marriage and the Family 53:91-127.

Casper, L.M. and P. Cohen. 2000. "How Does POSSLQ Measure Up? Historical Estimates of Cohabitation." Demography 37: 237-245.

Cherlin, A.J. 1992. Marriage, Divorce, Remarriage. Cambridge, MA: Harvard University Press.

Fitch, C.A. and S. Ruggles. 2000. "Historical Trends in Marriage Formation: The United States 1850-1990." Pp. 59-88 in The Ties that Bind: Perspectives on Marriage and Cohabitation (L.J. Waite, ed.). New York: Aldine de Gruyter.

Harris, K.M., F. Florey, J. Tabor, P.S. Bearman, J. Jones, and J. R. Udry. 2003. The National Longitudinal Study of Adolescent Health: Research Design [WWW document]. URL: http://www.cpc.unc.edu/projects/addhealth/design.html.

Nock, S.L. 1995. “A Comparison of Marriages and Cohabiting Relationships.” Journal of Family Issues 16: 53-76.

Raley, R.K. 2000. "Recent Trends and Differentials in Marriage and Cohabitation: The United States." Pp. 19-39 in The Ties that Bind: Perspectives on Marriage and Cohabitation (L.J. Waite, ed.). New York: Aldine de Gruyter.

Rindfuss, R.R. and A. VandenHeuvel. 1990. "Cohabitation: A Precursor to Marriage or an Alternative to Being Single?" Population and Development Review 16: 703-726.

Smock, P.J. 2000. "Cohabitation in the United States: An Appraisal of Research Themes, Findings, and Implications." Annual Review of Sociology 26: 1-20.

U.S. Bureau of the Census. 1998. "Household and Family Characteristics: March 1998 
(Update)." Current Population Reports, P20-515. Washington, DC. 
Table 1. Relationship Intensity, Females Aged 18-26 (In Percent).

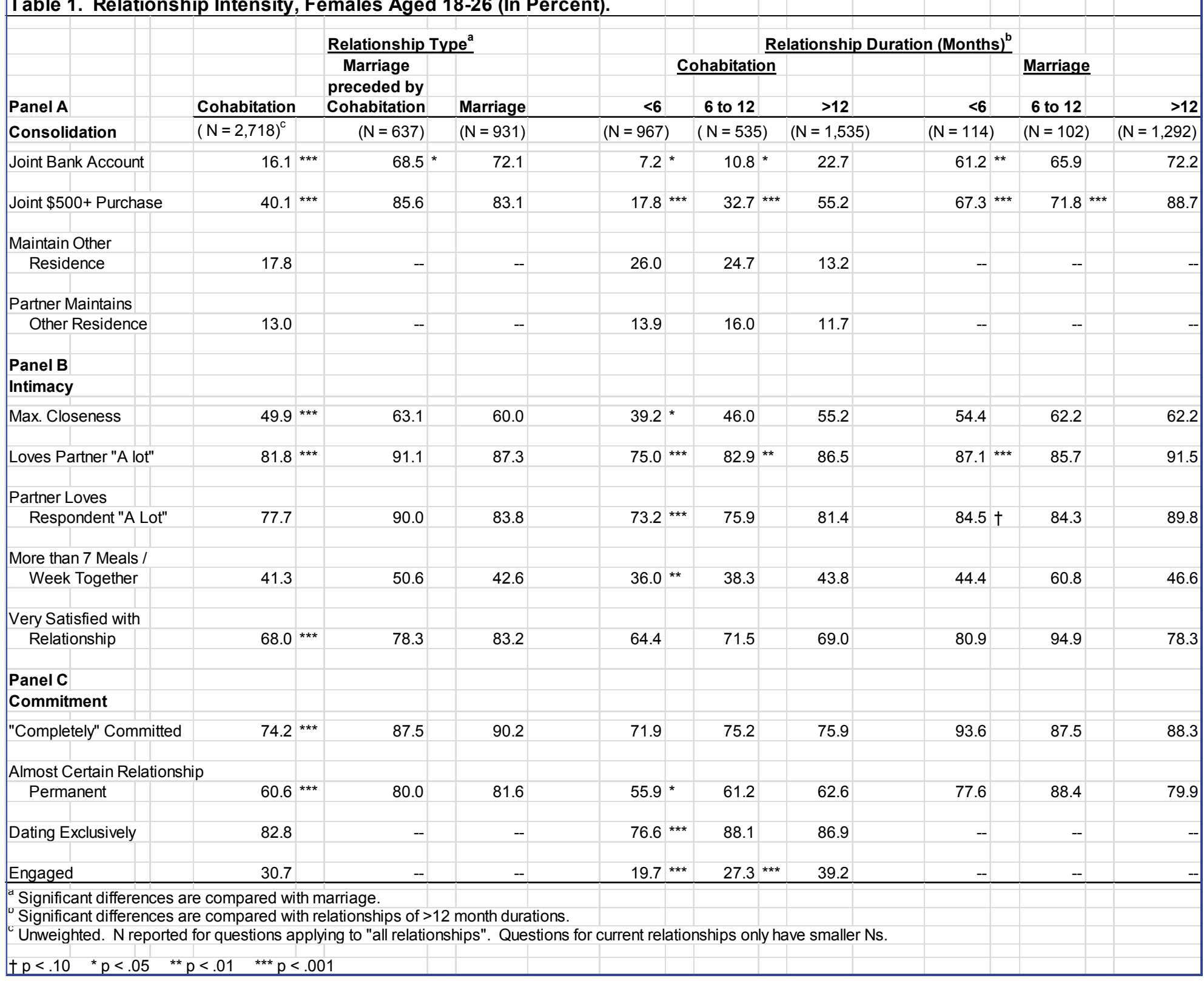




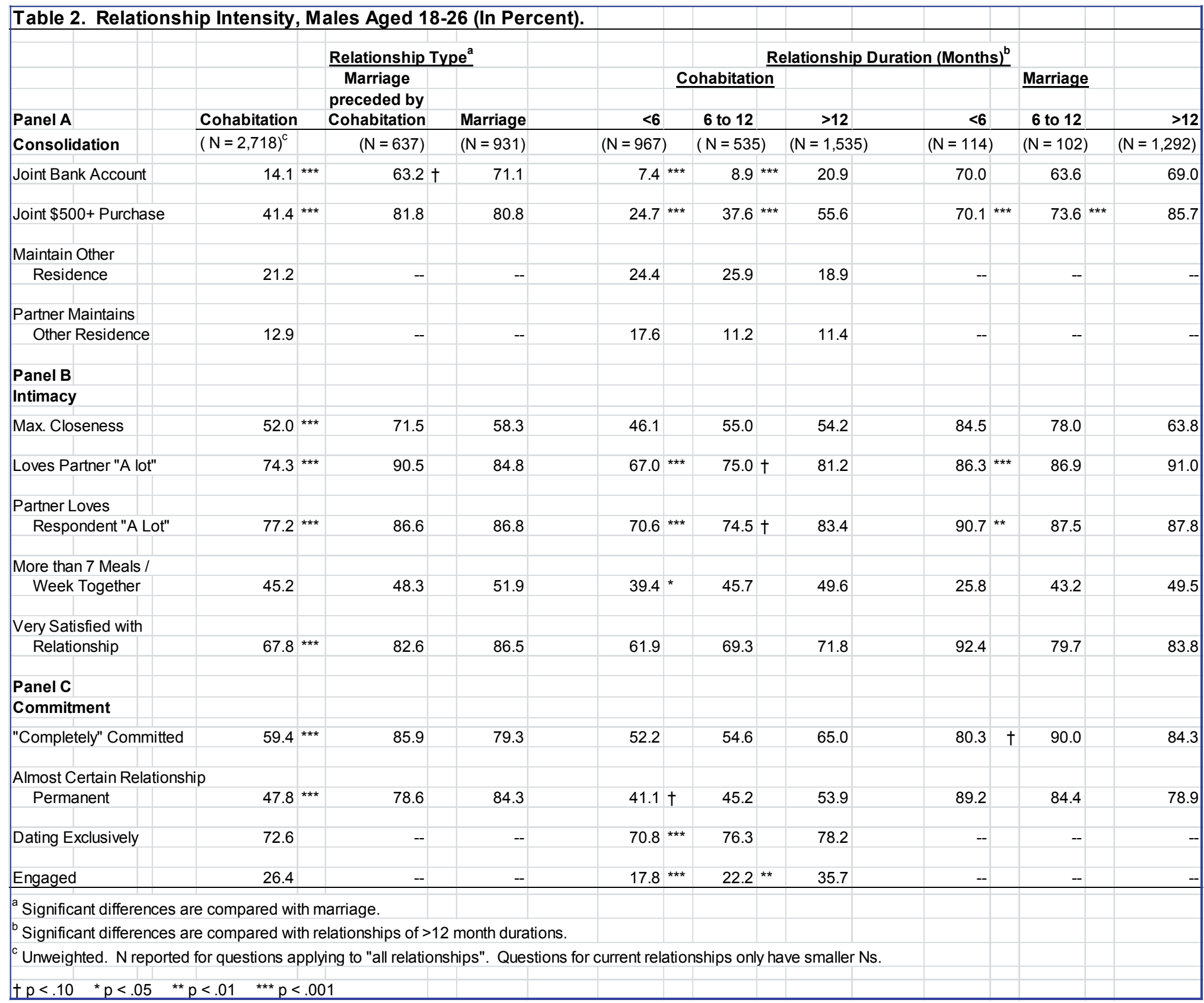



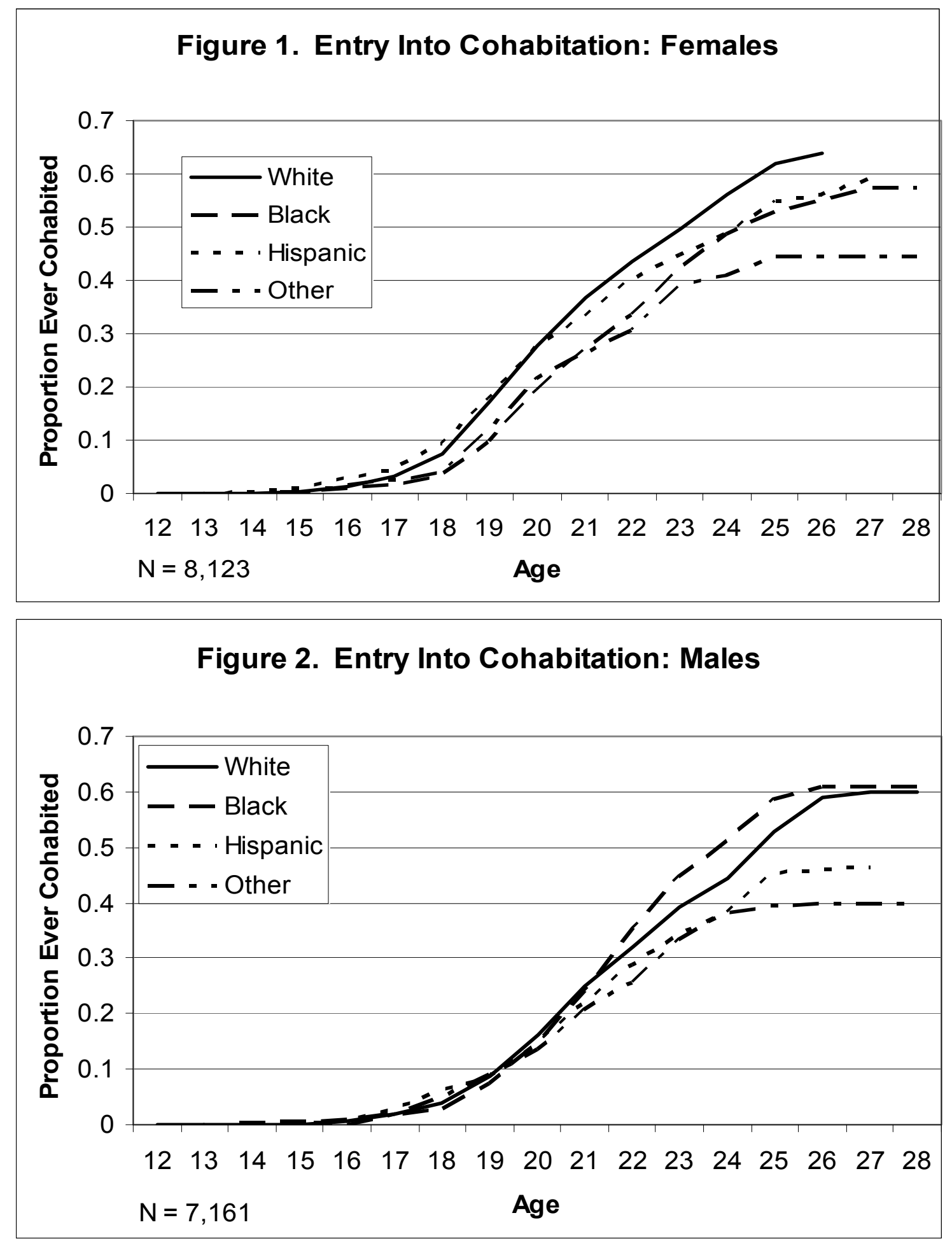


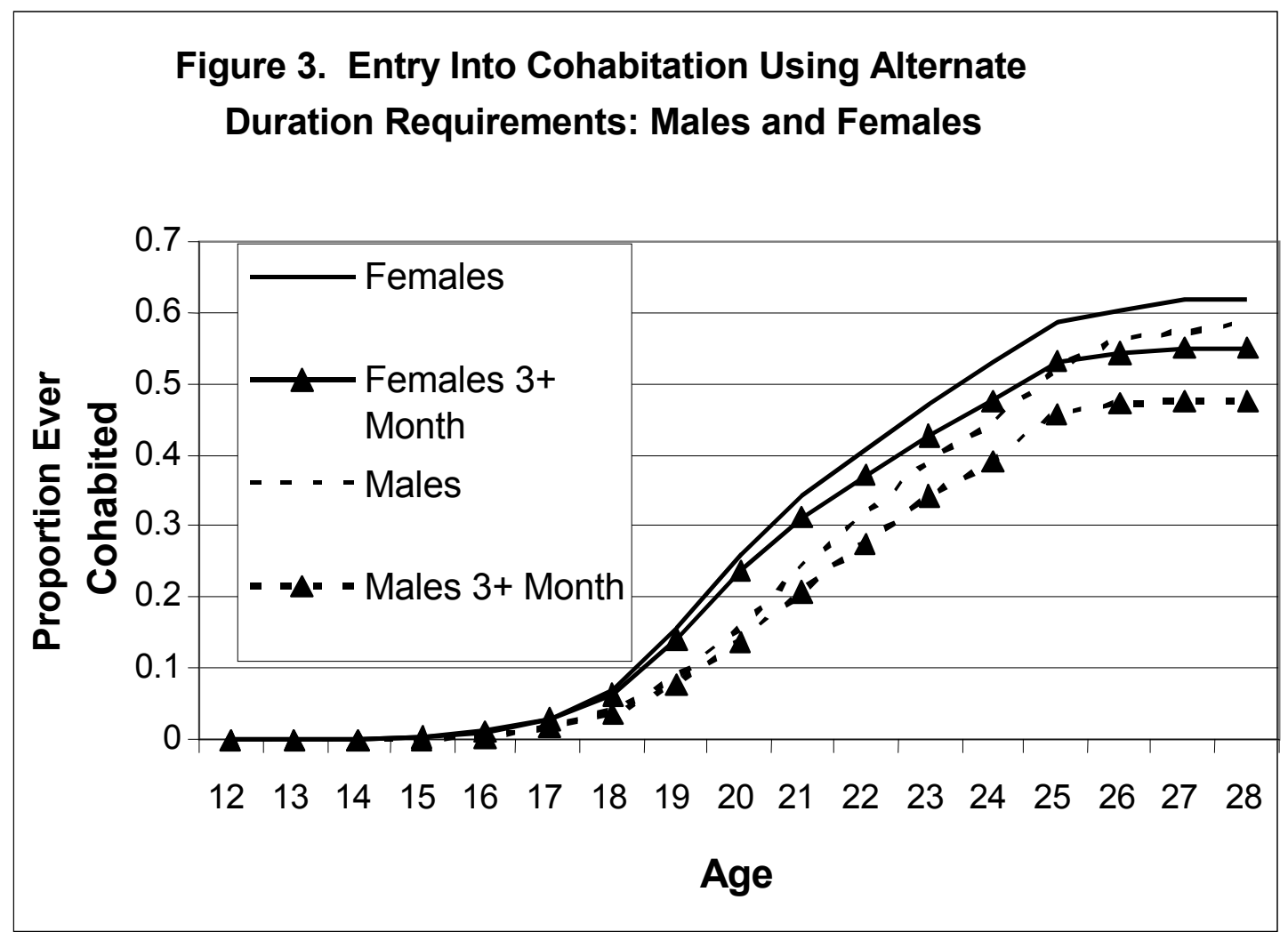


Figure 4A. Entry into Cohabitation by (Resident) Father's Education - FEM ALES

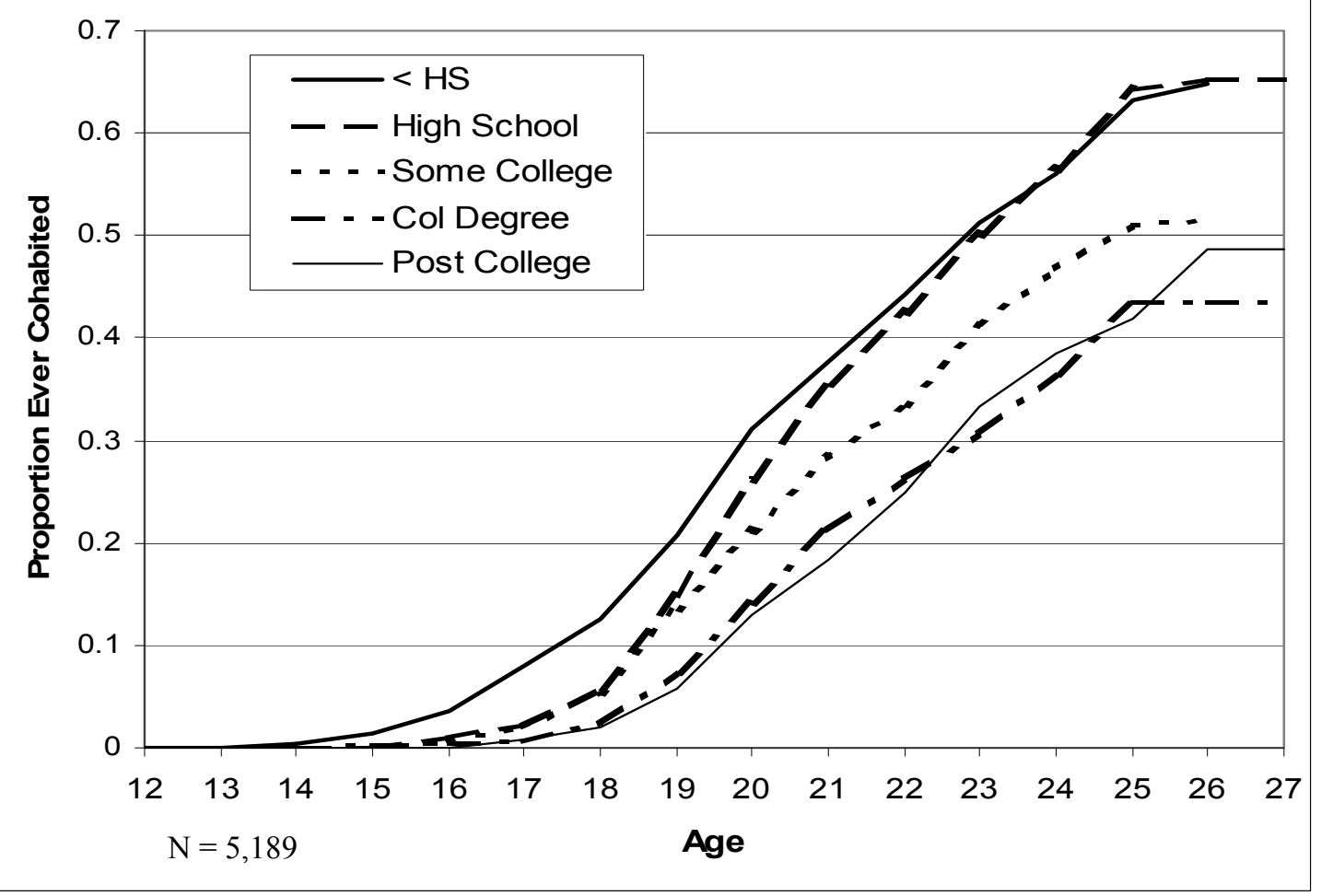

Figure 4B. Entry into Cohabitation by (Nonresident) Father's Educ - FEM ALES

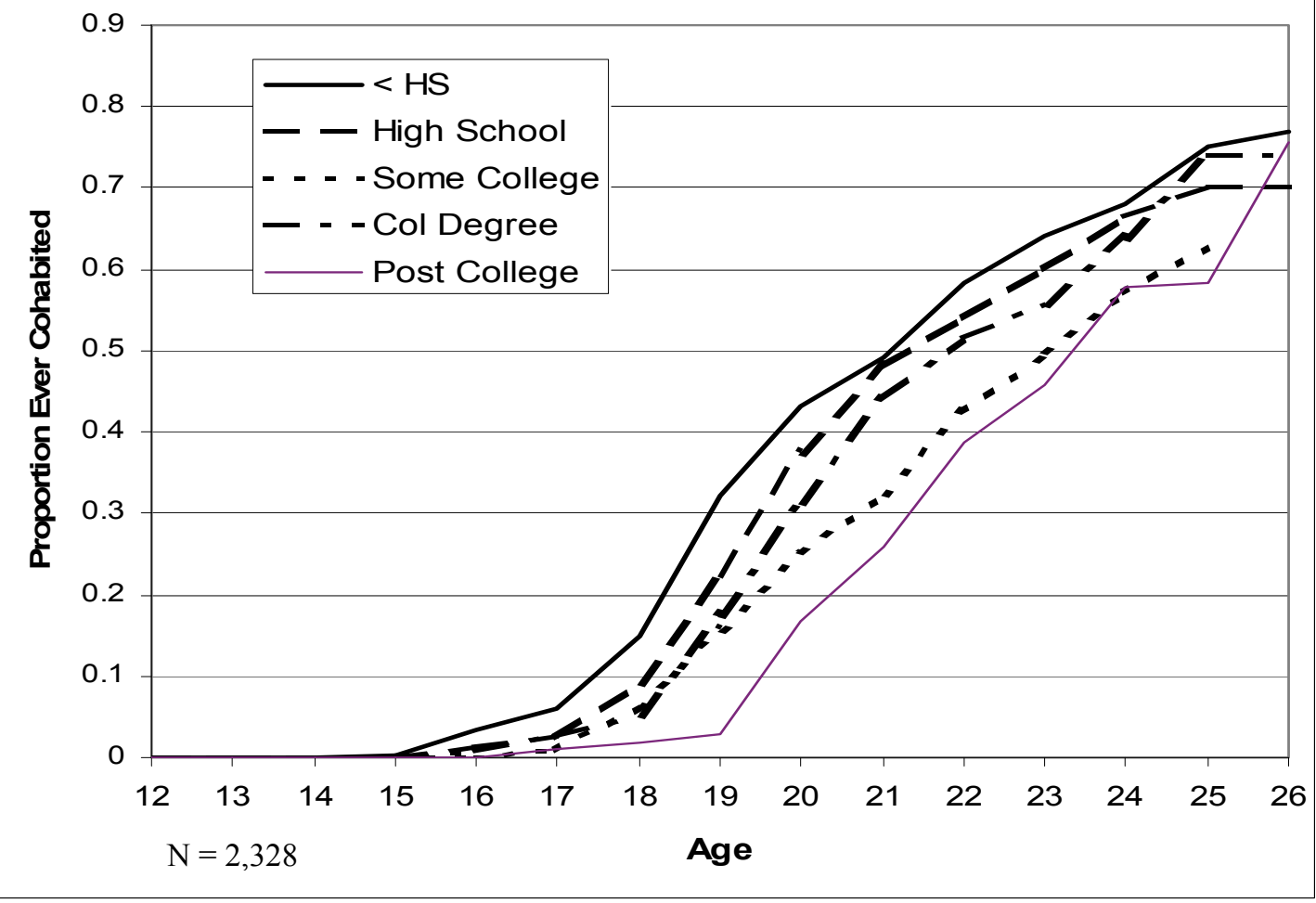



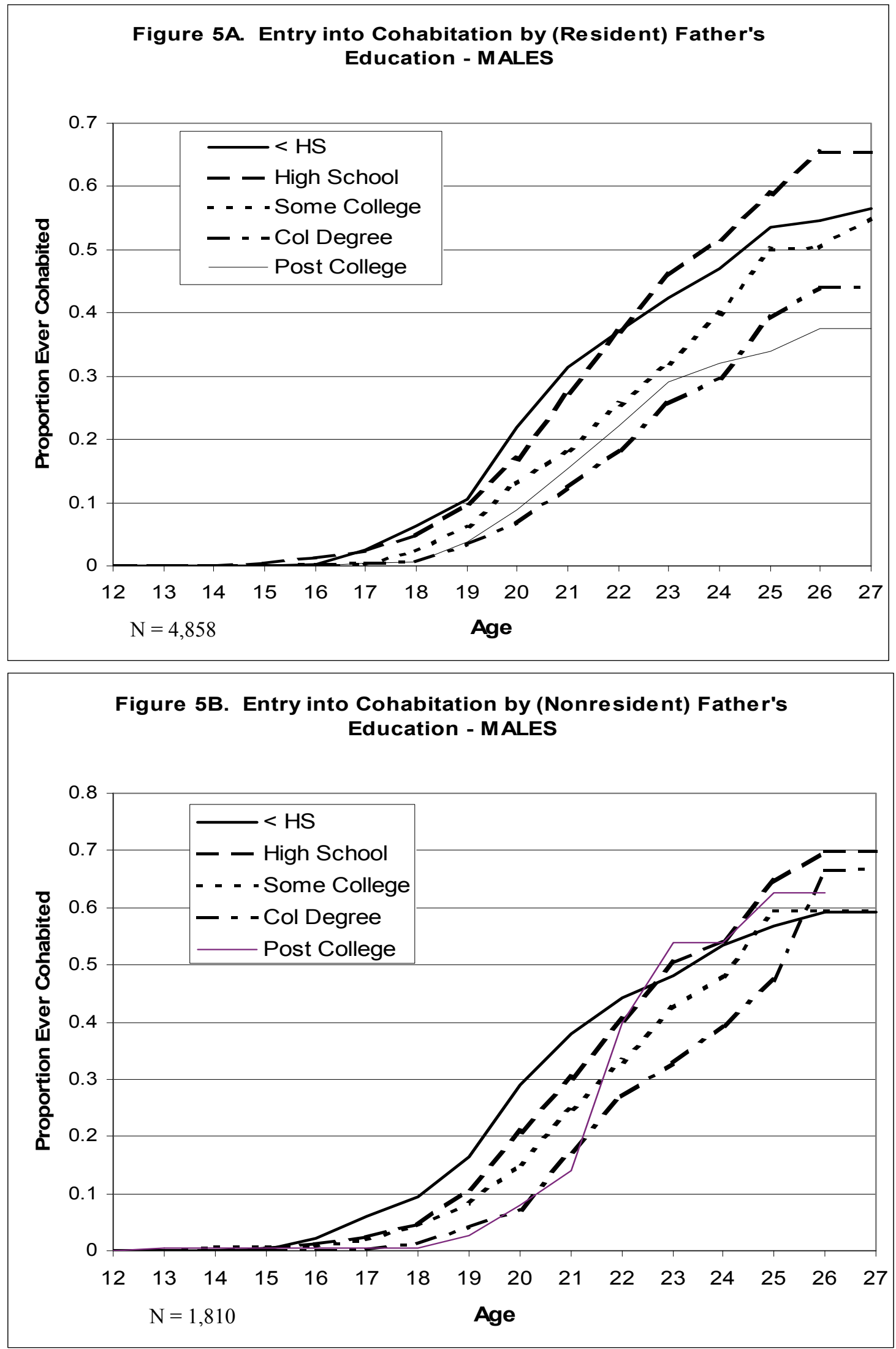